\title{
URBAN GOVERNANCE IN EUROPE: A THEORETICAL APPROACH AND BEST PRACTICES
}

Alina Esteves ${ }^{1}$

In a Europe where cities increasingly are the key elements in defining the structure and organisation of space, the book Governing European cities. Social fragmentation, social exclusion and urban governance ${ }^{2}$, edited by Hans Thor ANDERSEN and Ronald van KEMPEN in 2001, must be considered as highly relevant for all those with an active interest in social exclusion and urban governance.

This book is the result of the research work undertaken within the ambit of the EU action "COST A9 Civitas-Transformation of European Cities and Urban Governance", launched in 1995 by a group of researchers with the aim of assessing the reformulation of urban policy and governance in response to social, economic and demographic change in a number of European cities.

In fact, this is the third in a series of volumes that have sought to disseminate the findings of several researchers from 14 European countries (both within and outside the EU), from such diverse scientific fields as Geography, Sociology, Economics, Political Science, Urban Planning and Architecture.

Bearing in mind the tendency for the mechanisms that cause social exclusion and marginalisation to become increasingly present (and spatially apparent in the existence of housing areas that are the object of ethnic, social and economic segregation), the central goal of this book is to demonstrate just how dangerous it can be for European cities to disregard the existence and proliferation of social groups and areas/neighbourhoods that are marginalized from the decision-making processes. At the same time, the authors have sought to point out some of the options available to decision-makers, citizens and NGOs in order to tackle this deficit of participation by fostering the involvement of all citizens and spatial areas.

The 15 chapters that make up the book Governing European Cities, each written by a different author, are grouped into three different parts. The first one (Chapters 2 to 5) is a broad theoretical overview of the issues of social exclusion/ spatial fragmentation, in which the authors (J. Friedrichs and J. Vranken) seek to clarify some of the key concepts in this field (e.g., poverty, social exclusion, social participation/inclusion) and to make some general remarks with regard to the relationships between these concepts. Active

1 Teacher at the Faculdade de Letras, Universidade de Lisboa [University of Lisbon, College of Humanities]. Researcher at the Centro de Estudos Geográficos [Centre of Geographic Studies]. Address: Centro de Estudos Geográficos, Faculdade de Letras, Cidade Universitária, 1600-214 Lisbon. Tel: (351-1) 7940218; Fax: (351-1) 7938690. E-mail address: alinaesteves@eurodivisal.com.

2 Andersen, H. T.; van Kempen, R. (2001)-Governing European cities. Social fragmentation, social exclusion and urban governance. Aldershot, Ashgate. 
citizenship, based on networks and partnerships between the various social actors - individuals, govern-ments and non-governmental organisations -, is considered a key element of urban governance. R. van Kempen analyses the causes of social exclusion at a variety of different levels - from the global developments that define the role and position of each city within the world system, to those affecting the central and city governments, to local/neighbourhood dynamics - and comes to the conclusion that the characteristics of exclusion vary significantly from one geographical space to another, which calls for urban governance as a means to bring local actors into the process. Nevertheless, $M$. Blanc maintains that urban governance must always be subordinate to government, so that the various actors (NGOs, private corporations, associations) are refrained from pursuing their own interests rather than those of the community.

In the second part of the book (Chapters 6 to 14), several case studies are presented as examples of best practices in urban governance in such diverse cities as Amsterdam, Rotterdam, Vienna, Munich, Oslo and Barcelona. An important lesson that can be drawn from these case studies is that the local context plays a key role in determining the ultimate success of the initiatives, insofar as the participation of (and ownership by) the local actors varies to a great extent. Burges and Musterd, in fact, present a multi-level analytical model with the aim of interpreting social and spatial inequalities in a series of different cities. Alongside the differences in terms of social and cultural capital from one social group to another, one must take into account institutional aspects such as the role and scope of the welfare state or the historical evolution of the labour market and social infrastructure and facilities in each city. As a consequence, best practices cannot simply be "transplanted" from one city to another without fully understanding the factors that made it possible for such practices to be successful in a given context and without critically assessing those factors that may prevent those same practices from being successful in another context.

The third and last part of this book, co-written (as the introduction - chapter 1) by the two authors, seeks to draw some general conclusions and, in so doing, to point the way to the future of urban governance. Can it effectively curb social exclusion and fragmentation and help build more cohesive societies and territories? And can it - indeed, should it - replace the current forms of urban government?

There are no straightforward answers to these questions, but the analysis of the European case studies presented in this book shows that the local policy setting has a decisive impact upon which types and forms of governance are ultimately successful and which are not. Urban governance, as an innovative form of policy-making, has the dual advantage of mobilising human and financial resources at the local level, while bringing into the decision-making process citizens and associations that were previously neglected.

As for the legitimacy of urban governance to replace the current forms of government, the authors clearly assert that because the networks and partnerships between the local actors (public authorities, private sector, NGOs) are not the result of democratic elections, they should play a subordinate role with regard to representative democracy, insofar as they tend to advance the rights of the groups directly involved, rather than those of the community in general. Moreover, access to and participation in the partnerships is often limited to those actors that are already involved in the decision-making process, leaving out those that were excluded from it from the beginning.

Still, in spite of these weaknesses, urban governance is a positive way to extend political participation to citizens that, while being the target of urban policies, are normally left outside the process of designing those policies. It therefore creates additional opportunities for active citizenship and for the adoption of policies that are better suited to the needs of all of us - not just those closer to the decision-making circles. 